Trinity University

Digital Commons @ Trinity

Chemistry Faculty Research

Chemistry Department

9-2014

\title{
The Critical Role of Water at the Gold-titania Interface in Catalytic CO Oxidation
}

Johnny Saavedra

TrinityUniversity, jsaaved1@trinity.edu

H. Doan

Christopher J. Pursell

TrinityUniversity, cpursell@trinity.edu

L. C. Grabow

Bert D. Chandler

Trinity University, bchandle@trinity.edu

Follow this and additional works at: https://digitalcommons.trinity.edu/chem_faculty

Part of the Chemistry Commons

\section{Repository Citation}

Saavedra, J., Doan, H.A., Pursell, C.J., Grabow, L.C., \& Chandler, B.D. (2014). The Critical Role of Water at the Gold-titania Interface in Catalytic CO Oxidation. Science, 345, 1599-1602. doi: 10.1126/science.1256018

This Article is brought to you for free and open access by the Chemistry Department at Digital Commons @ Trinity. It has been accepted for inclusion in Chemistry Faculty Research by an authorized administrator of Digital Commons @ Trinity. For more information, please contact jcostanz@trinity.edu. 


\section{The critical role of water at the gold-titania interface in catalytic CO oxidation}

\begin{abstract}
Johnny Saavedra, ${ }^{1}$ Hieu A. Doan, ${ }^{2}$ Christopher J. Pursell, ${ }^{1}$ Lars C. Grabow, ${ }^{2 *}$ Bert D. Chandler ${ }^{1 *}$
We provide direct evidence of a water-mediated reaction mechanism for room-temperature $\mathrm{CO}$ oxidation over $\mathrm{Au} / \mathrm{TiO}_{2}$ catalysts. A hydrogen/deuterium kinetic isotope effect of nearly 2 implicates $\mathrm{O}-\mathrm{H}(\mathrm{D})$ bond breaking in the rate-determining step. Kinetics and in situ infrared spectroscopy experiments showed that the coverage of weakly adsorbed water on $\mathrm{TiO}_{2}$ largely determines catalyst activity by changing the number of active sites. Density functional theory calculations indicated that proton transfer at the metal-support interface facilitates $\mathrm{O}_{2}$ binding and activation; the resulting Au-OOH species readily reacts with adsorbed Au-CO, yielding $\mathrm{Au}-\mathrm{COOH}$. Au- $\mathrm{COOH}$ decomposition involves proton transfer to water and was suggested to be rate determining. These results provide a unified explanation to disparate literature results, clearly defining the mechanistic roles of water, support $\mathrm{OH}$ groups, and the metal-support interface.
\end{abstract}

T he interactions between transition-metal nanoparticles and their metal-oxide supports are often critical for heterogeneous metal nanoparticle catalysts (1). However, the roles of the species involved are often not well understood, especially for supported $\mathrm{Au}$ catalysts, which are active for selective hydrogenations $(2,3)$, oxidations $(3-5)$, and the watergas shift (WGS) reaction $(3,6)$. Several factors have been suggested for the exceptionally high activity of Au catalysts, including quantum size effects (7), particle geometry $(8,9)$, and undercoordinated $\mathrm{Au}$ atoms (10-12).

Oxygen activation at the metal-support interface is widely regarded as the key step in roomtemperature $\mathrm{CO}$ oxidation (13-17), but substantial debate remains regarding the nature of the active site $(9,12,17-23)$. Experimental studies indicate that materials lacking $\mathrm{OH}$ groups are inactive $(24,25)$, yet, the dominant mechanistic models vary in the suggested role of support $\mathrm{OH}$ groups and generally highlight the possible role of oxygen vacancies $(16,17,22-24,26)$. Computational models also have not indicated a clear mechanistic role for the support $\mathrm{OH}$ groups, and isotopelabeling studies indicate that $\mathrm{CO}$ and $\mathrm{O}_{2}$ react without incorporating oxygen from the support $(21,27)$. Perhaps most importantly, as Fig. 1A shows, water markedly increases catalytic activity $(20,21,26,27)$, yet only one proposed mechanism suggests a direct potential role for water $(21)$.

We performed an experimental and computational study to better understand how water, surface hydroxyls, and the metal-support interface interact during $\mathrm{CO}$ oxidation over $\mathrm{Au} / \mathrm{TiO}_{2}$

${ }^{1}$ Department of Chemistry, Trinity University, San Antonio, TX 78212-7200, USA. ${ }^{2}$ Department of Chemical and Biomolecular Engineering, University of Houston, Houston, TX 77204-4004, USA.

*Corresponding author. E-mail: bert.chandler@trinity.edu (B.D.C.); grabow@uh.edu (L.C.G.) catalysts. The surface water and hydroxyl groups of a commercial $\mathrm{Au} / \mathrm{TiO}_{2}$ catalyst were deuterated in situ with flowing $\mathrm{D}_{2} \mathrm{O} / \mathrm{N}_{2}$ [supplementary materials (SM) 3.1 and 3.2]. The exchanged catalyst was then flushed with $\mathrm{N}_{2}$ to remove excess $\mathrm{D}_{2} \mathrm{O}$. Under these conditions, we measured a large kinetic isotope effect $\left(\mathrm{KIE}, k_{\mathrm{H}} / k_{\mathrm{D}}=1.8 \pm 0.1\right.$, Fig.
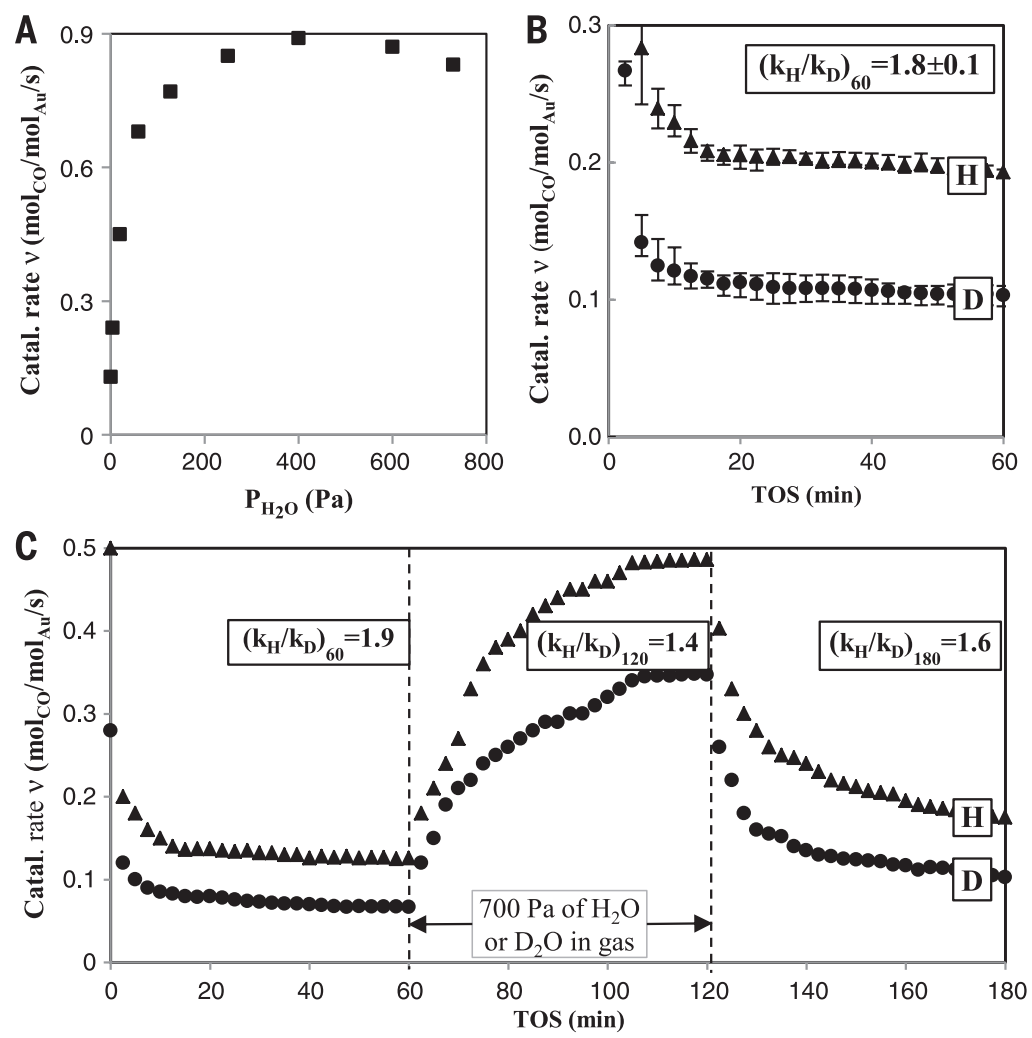

Fig. 1. Water and kinetic isotopic effects on $\mathrm{CO}$ oxidation over $\mathrm{Au} / \mathrm{TiO}_{2}$. (A) Effects of water on the overall reaction rate. (B) Reaction rate for protonated $(\mathbf{\Delta} \mathbf{H})$ and deuterated $(\bullet \mathbf{D})$ catalysts in the absence of added water (six trials averaged). (C) Changes in reaction rate induced by adding $700 \mathrm{~Pa}$ of $\mathrm{H}_{2} \mathrm{O} / \mathrm{D}_{2} \mathrm{O}$. Reaction conditions: $20^{\circ} \mathrm{C}, 1 \% \mathrm{CO}, 20 \% \mathrm{O}_{2}$, space velocity $(\mathrm{SV})=36$ liters g catalyst -1 min -1 . 
The $\mathrm{H}_{2} \mathrm{O}$ molecule adsorbed on a bridging $\mathrm{OH}$ group at the metal-support interface through hydrogen bonding interactions; this adsorption motif was $\sim 1.0 \mathrm{eV}$ more stable than adsorption on the Au cluster and $\sim 1.4 \mathrm{eV}$ more stable than adsorption on a bridging $\mathrm{OH}$ group away from the interface (SM 6.1). Although we studied several $\mathrm{O}_{2}$ adsorption and activation pathways (Fig. 2, SM 6.2 and 6.3), we did not find an intermediate species with $\mathrm{O}_{2}$ bound only to $\mathrm{Au}$ atoms near the metal-support interface. In all cases, an essentially barrier-free proton transfer lowered the overall energy of the system, generating $\mathrm{H}_{2} \mathrm{O}_{2}{ }^{*}$ or ${ }^{*} \mathrm{OOH}$ (Fig. 2; “*”" references species adsorbed to $\mathrm{Au}$ ). Once ${ }^{*} \mathrm{OOH}$ formed, it migrated along the Au particle, allowing atoms near, but not strictly at, the metalsupport interface to participate in the reaction.

The KIE and DFT studies indicate proton transfer in a key reaction step, but they do not provide sufficient information to determine if the reaction is initiated by adsorbed water or support $\mathrm{OH}$ groups. In situ infrared spectroscopy was therefore used to quantify these species (SM 4.1) and compare catalyst activity to their relative surface concentrations. The non-hydrogen-bonded $v_{\mathrm{OH}}$ stretching vibration centered near $3650 \mathrm{~cm}^{-1}$ is exclusively associated with support $\mathrm{OH}$ groups, whereas the $\delta_{\mathrm{HOH}}$ bending vibration centered at $1623 \mathrm{~cm}^{-1}$ is exclusively due to adsorbed water. There is also a broad band centered around $3400 \mathrm{~cm}^{-1}$ assigned to $v_{\mathrm{OH}}$ for $\mathrm{OH}$ groups involved in hydrogen bonding that may have contributions from both water and Ti-OH [complete infrared (IR) analysis in SM 4.1].

Our catalysis studies do not indicate a direct role for support $\mathrm{OH}$ groups in the reaction mechanism. Gentle drying with flowing $\mathrm{N}_{2}$ (Table 1 and Fig. 3A) only removed water and had little effect on the support $\mathrm{OH}$ bands. Catalytic activity, however, dropped by an order of magnitude, indicating that adsorbed water, not support $\mathrm{OH}$, is the key proton donor. Further, a constrained ab initio thermodynamic analysis (SM 2.6) indicates that the support $\mathrm{OH}$ groups at the metalsupport interface are thermodynamically unstable relative to gas-phase water under dry conditions and therefore would be unavailable as proton donors. As water is added to the system, the interfacial support $\mathrm{OH}$ groups and weakly adsorbed water are equilibrated and ultimately become indistinguishable.

Several mechanisms reported in the literature invoke $\mathrm{OH}$ transfer from the support to $\mathrm{Au}$ $(17,23)$ as an elementary step. Our experimental and DFT studies do not support such a step. The calculated barrier for transferring a $\mathrm{Ti}^{\text {cus }}-\mathrm{OH}$ group to $\mathrm{Au}$ [activation energy $\left(E_{\mathrm{a}}\right)=1.63 \mathrm{eV}$, SM 6.5] is too large to be a viable room-temperature pathway. Further, generating ${ }^{*} \mathrm{COOH}$ from ${ }^{*} \mathrm{CO}$ and ${ }^{*} \mathrm{OOH}\left(\Delta E=-2.23 \mathrm{eV}, E_{\mathrm{a}}=0.10 \mathrm{eV}\right)$ is thermodynamically and kinetically far more favorable than the reaction between ${ }^{*} \mathrm{CO}$ and $\mathrm{Ti}^{\text {cus }}-\mathrm{OH}(\Delta E=$ $0.60 \mathrm{eV}, E_{\mathrm{a}}=0.72 \mathrm{eV}, \mathrm{SM} 6.5$ ).

To quantify the effects of adsorbed water, we performed a series of adsorption, thermogravimetric analysis (TGA), and kinetics experiments. IR spectroscopy showed water adsorption on titania (not on $\mathrm{Au}, \mathrm{SM} 4.1$ ), consistent with DFT calculations (SM 6.1). The adsorption isotherm quasi-saturated around $700 \mathrm{~Pa}$ (1.7 weight \%, 13 molecules $/ \mathrm{nm}^{2}$ ), corresponding to roughly 1.5 monolayers of water on titania, suggesting a bilayer adsorption structure typical for water (30). The reaction rate correlates extremely well with the amount of weakly adsorbed water, and the reaction order (1.33, Fig. 3B) is substantially larger than the reaction orders for $\mathrm{CO}$ or $\mathrm{O}_{2}$ (0.01 and 0.1 to 0.3 , respectively; SM 5.1 to 5.3).

We further evaluated the reaction kinetics using a Michaelis-Menten (M-M) kinetic model (SM 5.2), which provides quantitative metrics that characterize heterogeneous catalysts (31). This model helps distinguish between changes in the inherent activity of the active site (measured with $K_{\mathrm{R}}$-analogous to the conventional $K_{\mathrm{M}}$ ) and the relative number of active sites (associated with $\left.v_{\max }\right)$. Double-reciprocal plots of the $\mathrm{O}_{2}$ dependence data (Fig. $3 \mathrm{C}$ ) yield $K_{\mathrm{R}}$ values that are independent of the water coverage (Fig. 3D), indicating that $\mathrm{H}_{2} \mathrm{O}$ did not affect the inherent reactivity of the active sites. The $v_{\max }$ values, however, increased linearly with adsorbed water. Because $K_{\mathrm{R}}$ was essentially constant, this indicates that weakly adsorbed water increased the effective number of active sites rather than changing their inherent reactivity.

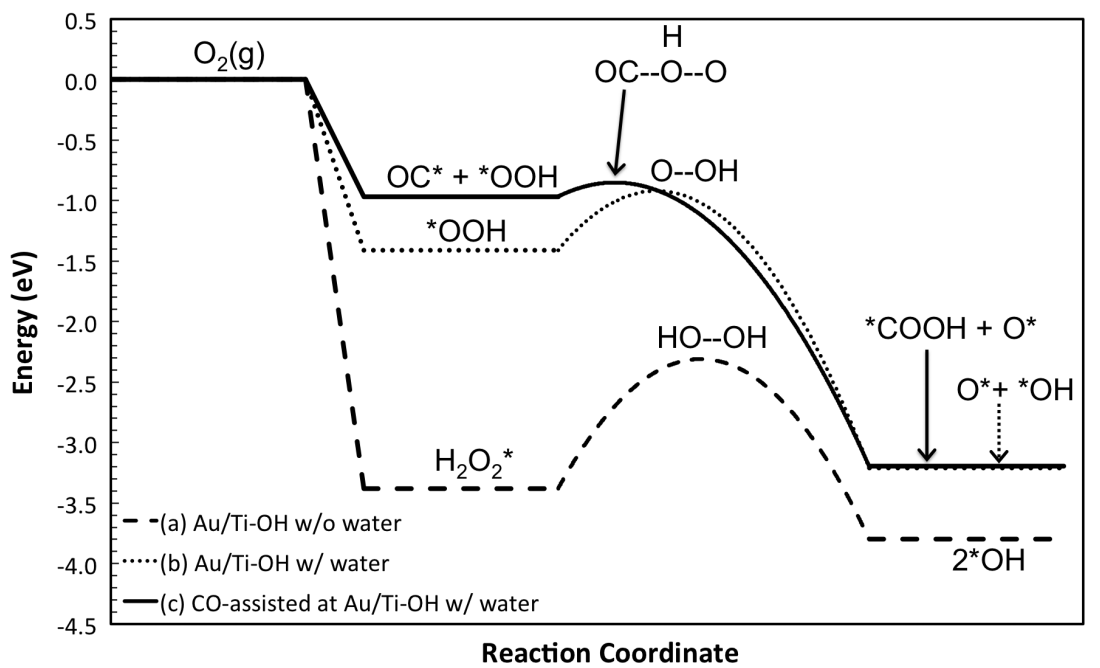

Fig. 2. Potential energy diagrams for $\mathrm{O}_{2}$ binding and $\mathrm{O}-\mathrm{O}$ bond activation near the $\mathrm{Au} / \mathrm{TiO}_{2}$ interface. (a): In the absence of $\mathrm{H}_{2} \mathrm{O}$ (dashed pathway), $\mathrm{O}_{2}$ adsorption at the $\mathrm{Au} / \mathrm{TiO}_{2}$ interface initiates a spontaneous transfer of two protons, forming $\mathrm{H}_{2} \mathrm{O}_{2}{ }^{*}$; (b): with an adsorbed $\mathrm{H}_{2} \mathrm{O}$ (dotted pathway), O-O bond activation leads preferentially to $\mathrm{O}^{*}$ and ${ }^{*} \mathrm{OH}$; (c): with adsorbed $\mathrm{H}_{2} \mathrm{O}$ and $\mathrm{CO}$ (solid pathway), O-O scission is facilitated by nucleophilic attack of ${ }^{*} \mathrm{CO}$, resulting in ${ }^{*} \mathrm{COOH}$ (carboxyl).

Table 1. Effects of drying treatments on IR spectra and catalytic activity.

\begin{tabular}{|c|c|c|c|}
\hline Drying treatment* & $\mathrm{Ti}-\mathrm{OH}$ area ${ }^{\dagger}$ & $\mathrm{H}_{2} \mathrm{O}$ area $^{\ddagger}$ & $v\left(s^{-1}\right)$ \\
\hline None & 14.3 & 842 & 0.32 \\
\hline $20^{\circ} \mathrm{C}, 0.5$ hour & 14.1 & 503 & 0.22 \\
\hline $70^{\circ} \mathrm{C}, 0.5$ hour & 14.0 & 228 & 0.18 \\
\hline $20^{\circ} \mathrm{C}, 16$ hours & 13.9 & 131 & 0.09 \\
\hline $70^{\circ} \mathrm{C}, 16$ hours & 13.8 & 102 & 0.03 \\
\hline
\end{tabular}

${ }^{*} \mathrm{~N}_{2}$ flowing at $50 \mathrm{ml} / \mathrm{min} . \quad \$ 3741-3645 \mathrm{~cm}^{-1} . \quad \$ 3800-1800 \mathrm{~cm}^{-1}$
Two explanations for increasing the number of active sites are consistent with the DFT studies recognize the importance of the metal-support in $(9,12,18-23)$. First, if oxygen binding then increasing the water coverage should increase the number of available protons and facilitate $\mathrm{O}_{2}$ binding. Second, the DFT studies suggest OOH can interact with $\mathrm{Au}$ atoms that are face. As additional Au sites gain access to protons from water, a greater number of $\mathrm{O}_{2} /$ peroxo-binding sites become available. This increase in activesite density also argues strongly against $\mathrm{O}$ atom vacan support being the active sites pected to rapidly fill those vacancies.

The conclusion that support $\mathrm{OH}$ groups do not directly participate in the reaction mechanism rees a new model to explain why the support activity $(13-15,24,25)$. Our results indicate that the support $\mathrm{OH}$ groups' primary role is to anchor active water near the Au particle and possibly help activate it through hydrogen bonding. The relative to support OHs near Au particles and their ability to anchor enough water to facilitate the reaction may partially explain the strong support effects reported in the literature $(3,17,22,23)$. 
Although the DFT results for $\mathrm{O}_{2}$ adsorption are congruent with proton transfer as part of the mechanism, they do not explain the observed KIE. The ${ }^{*} \mathrm{OOH}$ species have moderate direct decomposition barriers $\left(E_{\mathrm{a}} \sim 0.5 \mathrm{eV}\right.$, Fig. 2
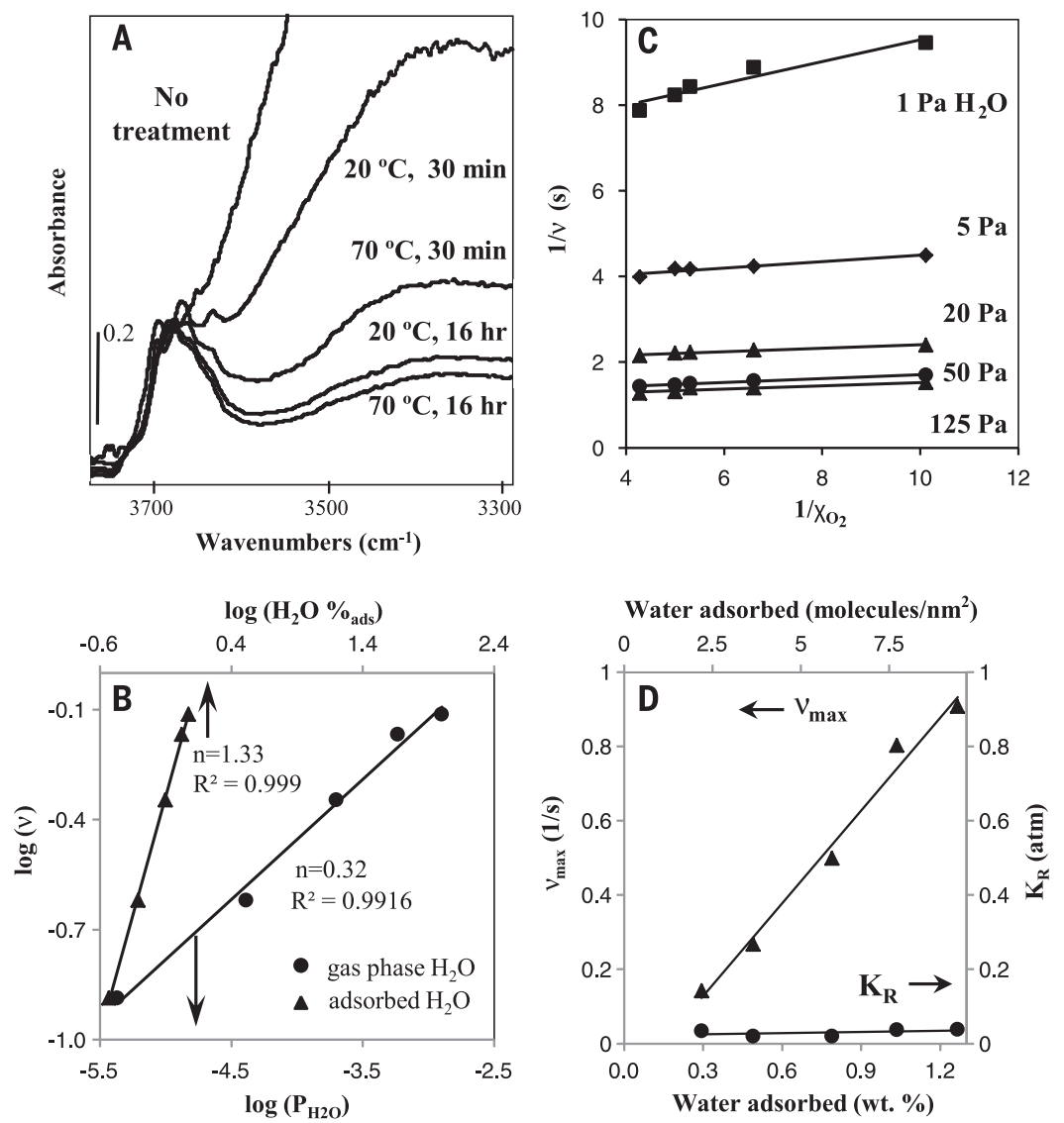

Fig. 3. Infrared spectroscopy and kinetics data showing the changes associated with weakly adsorbed water. (A) IR spectra and treatment conditions for gently dried catalysts. (B) Reaction order based on gas phase $(\bullet)$ and weakly adsorbed $(\boldsymbol{\Delta})$ water $\left(20^{\circ} \mathrm{C}, 1 \% \mathrm{CO}, 20 \% \mathrm{O}_{2}\right.$, SV $=35$ liters $\mathrm{g}$ catalyst ${ }^{\mathbf{- 1}} \mathrm{min}^{\mathbf{- 1}}$ ). (C) Double-reciprocal plots used in Michaelis-Menten kinetic treatment. (D) MichaelisMenten kinetic parameters versus catalyst water content. dissociation on supported and unsupported $\mathrm{Au}$ clusters $(10,13,14,18,32)$. In contrast to the predominant opinion reported in the literature (16), the extremely low barriers associated with this pathway suggest that $\mathrm{O}_{2}$ activation is quite facile in the presence of water and $\mathrm{CO}$.

To explain the observed KIE and close the catalytic cycle, we explored possible ${ }^{*} \mathrm{COOH}$ decomposition pathways (SM 6.6); Fig. 4 shows the two most relevant pathways. In the first pathway, the proton is spontaneously transferred from ${ }^{*} \mathrm{COOH}$ to the coadsorbed $\mathrm{O}^{*}$ (green, $\Delta \mathrm{E}=-0.27 \mathrm{eV}, E_{\mathrm{a}}=$ $0.0 \mathrm{eV}$ ), leaving ${ }^{*} \mathrm{OH}$ on the surface after $\mathrm{CO}_{2}$ desorption. Closing the catalytic cycle requires the direct reaction between ${ }^{*} \mathrm{OH}$ and ${ }^{*} \mathrm{CO}(\Delta E=$ $0.10 \mathrm{eV}, E_{\mathrm{a}}=0.40 \mathrm{eV}, \mathrm{SM} 6.4$ ) to yield ${ }^{*} \mathrm{COOH}$, followed by * $\mathrm{COOH}$ decomposition, which returns the proton and restores the active site. The second pathway is initiated by an endothermic proton transfer from ${ }^{*} \mathrm{COOH}$ to an adsorbed water molecule (simultaneously transferring a proton to the support) (purple, $\Delta E=0.61 \mathrm{eV} ; E_{\mathrm{a}}=0.76 \mathrm{eV}$ ), followed by $\mathrm{CO}_{2}$ desorption. The remaining $\mathrm{O}^{*}$ reacts with ${ }^{*} \mathrm{CO}$ in a well-studied reaction $(\Delta E=$ $\left.-1.03 \mathrm{eV} ; E_{\mathrm{a}}=0.65 \mathrm{eV}, \mathrm{SM} 6.4\right)$.

These pathways are chemically similar, differing primarily in the order of the steps. The reactions between ${ }^{*} \mathrm{CO}$ and ${ }^{*} \mathrm{O}$ or ${ }^{*} \mathrm{OH}$ have fairly similar barriers, and both pathways also go through the same endothermic ${ }^{*} \mathrm{COOH}$ decomposition step. This step is the likely RDS because it involves a proton transfer $\left({ }^{*} \mathrm{COOH}\right.$ to water) and has the highest computed activation-energy barrier (movie S1). DFT calculations based on this transition state (involving a single water molecule) yielded a calculated KIE of 2.55 (SM 6.7), which represents an upper limit to the experimentally determined KIE at low water coverage. The predicted lower limit of the equilibrium isotope effect associated with this step is 1.08 . This is somewhat lower than the value we measured at $700-\mathrm{Pa}$ water, but is similar to low values previously reported using higher water pressures (21, 28).

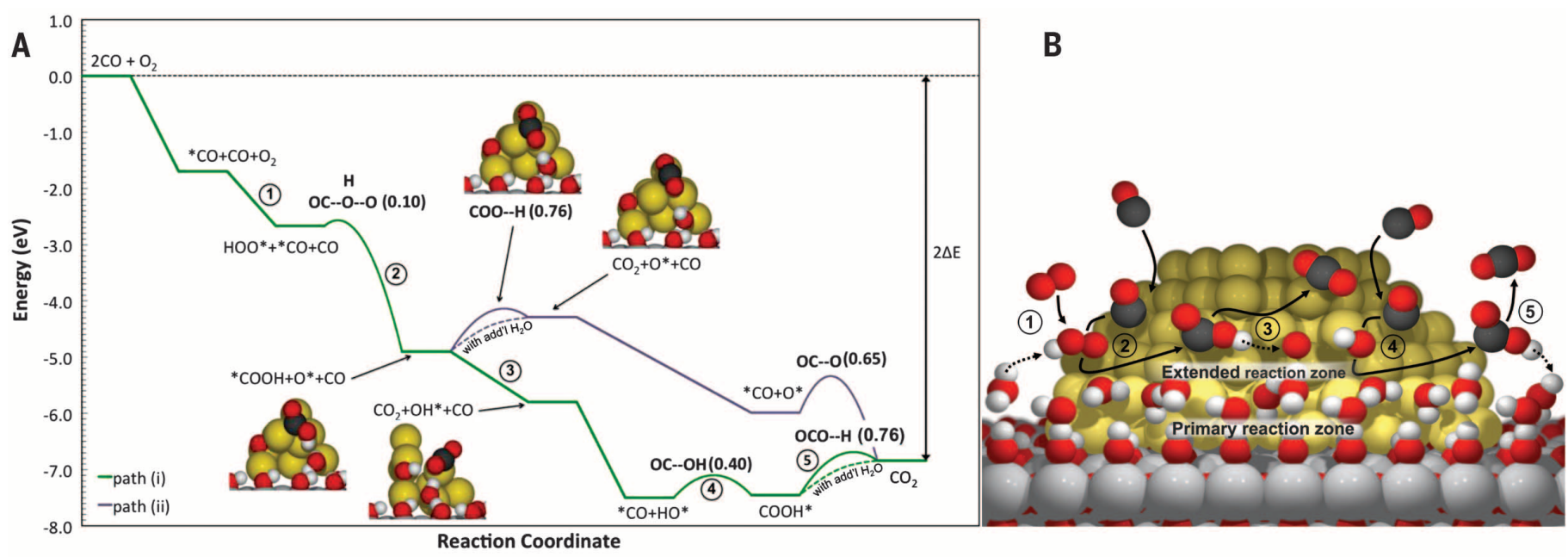

Fig. 4. Proposed reaction mechanism. (A) Potential energy diagram; both pathways are limited by a combination of ${ }^{*} \mathrm{COOH}$ decomposition and the reaction between ${ }^{*} \mathrm{CO}$ and ${ }^{*} \mathrm{O}(\mathrm{H})$. (B) Schematic representation of the lower (green) pathway. 
The involvement of weakly adsorbed water in multiple mechanistic steps is also consistent with the large reaction order (1.3). DFT calculations also indicate that a second adsorbed water molecule in the vicinity of the ${ }^{*} \mathrm{COOH}$ species facilitates the proton transfer, which only needs to overcome the thermodynamic barrier $(\Delta E=$ $0.70 \mathrm{eV}, E_{\mathrm{a}}=0.70 \mathrm{eV}, \mathrm{SM}$ 6.6). Further, at higher water coverage, rapid proton mobility (33) can explain the shift to an equilibrium isotope effect. ${ }^{*} \mathrm{COOH}$ decomposition has also been identified as the RDS in the related WGS reaction on $\mathrm{Cu}$ and Pt $(34,35)$, and this elementary step is consistent with reports of $\mathrm{NaOH}$ promoting $\mathrm{CO}$ oxidation over Au catalysts $(17,36)$.

The $\mathrm{CO}$ oxidation mechanism shown in Fig. 4, along with the structural model of support $\mathrm{OH}$ groups anchoring and activating water near $\mathrm{Au}$ particles, provides a fresh framework for interpreting previous results. This model provides a single active-site description that unifies some very disparate mechanistic information, accounts for the promotional effects of water, and is consistent with previously reported isotope exchange studies $(21,27)$ that indicate that $\mathrm{CO}$ and $\mathrm{O}_{2}$ must react directly on the Au particles without exchanging $\mathrm{O}$ atoms with the support or adsorbed water. At the same time, it maintains the importance of the support $\mathrm{OH}$ groups and the metal-support interface without directly involving them in the reaction mechanism. The likely active sites bear a strong resemblance to the WGS mechanism over $\mathrm{Au}$ catalysts, where the support anchors water near Au-CO sites (6).

This proposed mechanism explains why the $\mathrm{O}_{2}$ adsorption and activation steps, which are widely regarded as the critical mechanistic steps, have been so difficult to characterize. The fast roomtemperature catalysis mechanism requires both water and $\mathrm{CO}$ for $\mathrm{O}_{2}$ binding and activation. Experiments performed without water, particularly ultrahigh-vacuum and DFT studies, ultimately probe different reaction mechanisms than what appears to be the dominant room-temperature pathway on supported catalysts. Similarly, most traditional catalyst studies rarely control or report feedwater contents, which has likely contributed to the wide range of reported $\mathrm{CO}$ oxidation activities for $\mathrm{Au} / \mathrm{TiO}_{2}$ catalysts and to the difficulties in understanding the key features of the best catalysts. Finally, this new mechanism brings the interpretation of traditional supported catalyst experiments more in line with computational and surface-science studies, which have largely indicated that the key reaction steps occur on $\mathrm{Au}(7,9-14,17,29)$, without direct participation of the support.

\section{REFERENCES AND NOTES}

1. M. Cargnello et al., Science 341, 771-773 (2013).

2. A. Corma, P. Serna, Science 313, 332-334 (2006).

3. T. Takei et al., Adv. Catal. 55, 1-126 (2012).

4. B. N. Zope, D. D. Hibbitts, M. Neurock, R. J. Davis, Science 330 74-78 (2010).

5. C. Della Pina, E. Falletta, M. Rossi, Chem. Soc. Rev. 41 350-369 (2012)

6. M. Shekhar et al., J. Am. Chem. Soc. 134, 4700-4708 (2012)

7. M. Valden, X. Lai, D. W. Goodman, Science 281, 1647-1650 (1998).
8. A. A. Herzing, C. J. Kiely, A. F. Carley, P. Landon, G. J. Hutchings, Science 321, 1331-1335 (2008).

9. M. S. Chen, D. W. Goodman, Science 306, 252-255 (2004).

10. H. Falsig et al., Angew. Chem. Int. Ed. 47, 4835-4839 (2008)

11. C. Lemire, R. Meyer, S. Shaikhutdinov, H.-J. Freund, Angew. Chem. Int. Ed. 43, 118-121 (2004)

12. G. Mills, M. S. Gordon, H. Metiu, J. Chem. Phys. 118, 4198 (2003)

13. I. N. Remediakis, N. Lopez, J. K. Nørskov, Angew. Chem. Int. Ed 44, 1824-1826 (2005).

14. L. M. Molina, M. D. Rasmussen, B. Hammer, J. Chem. Phys. 120, 7673-7680 (2004).

15. R. A. Ojifinni et al., J. Am. Chem. Soc. 130, 6801-6812 (2008).

16. D. Widmann, R. J. Behm, Acc. Chem. Res. 47, 740-749 (2014)

17. M. S. Ide, R. J. Davis, Acc. Chem. Res. 47, 825-833 (2014).

18. I. X. Green, W. Tang, M. Neurock, J. T. Yates Jr., Science 333 , 736-739 (2011)

19. T. Fujitani, I. Nakamura, Angew. Chem. Int. Ed. 50, 10144-10147 (2011).

20. M. Daté, M. Okumura, S. Tsubota, M. Haruta, Angew. Chem. Int Ed. 43, 2129-2132 (2004)

21. M. Ojeda, B.-Z. Zhan, E. Iglesia, J. Catal. 285, 92-102 (2012)

22. M. C. Kung, R. J. Davis, H. H. Kung, J. Phys. Chem. C 111, 11767-11775 (2007).

23. M. Haruta, Faraday Discuss. 152, 11-32, discussion 99-120 (2011).

24. J. A. Singh, S. H. Overbury, N. J. Dudney, M. Li, G. M. Veith, ACS Catal. 2, 1138-1146 (2012)

25. W. C. Ketchie, M. Murayama, R. J. Davis, Top. Catal. 44 307-317 (2007)

26. H. H. Kung, M. C. Kung, C. K. Costello, J. Catal. 216, 425-432 (2003).

27. J. T. Calla, R. J. Davis, J. Catal. 241, 407-416 (2006)

28. C. K. Costello et al., Appl. Catal. A 243, 15-24 (2003).

29. S. Laursen, S. Linic, Phys. Chem. Chem. Phys. 11, 11006-11012 (2009).

30. J. Carrasco, A. Hodgson, A. Michaelides, Nat. Mater. 11, 667-674 (2012)

31. C. G. Long et al., J. Am. Chem. Soc. 130, 10103-10115 (2008).

32. Z.-P. Liu, P. Hu, A. Alavi, J. Am. Chem. Soc. 124, 14770-14779 (2002).

33. L. R. Merte et al., Science 336, 889-893 (2012).

34. A. A. Gokhale, J. A. Dumesic, M. Mavrikakis, J. Am. Chem. Soc. 130, 1402-1414 (2008)
35. L. C. Grabow, A. A. Gokhale, S. T. Evans, J. A. Dumesic M. Mavrikakis, J. Phys. Chem. C 112, 4608-4617 (2008). 36. G. M. Veith, A. R. Lupini, N. J. Dudney, J. Phys. Chem. C 113 , 269-280 (2009).

\section{ACKNOWLEDGMENTS}

We gratefully acknowledge the U.S. National Science Foundation (grants CBET-1160217, CHE-1012395, and CHE-1300619) and the U.S. Department of Energy (NSF/DOE CBET-1258688) for financial support of this work. We also thank R. Rioux (Pennsylvania State University) and Z. Tonzetich (University of Texas at San Antonio) for assistance with transmission electron microscopy and

thermogravimetric analysis measurements, respectively. Additional financial support was provided to L.C.G. and H.A.D. through a

University of Houston New Faculty Grant. Use of the computational resources at the Center for Nanoscale Materials was supported by the U.S. DOE, Office of Science, Office of Basic Energy Sciences, under contract no. DE-AC02-06CH11357. This work also used the Extreme Science and Engineering Discovery Environment (XSEDE, supported by NSF grant OCl-1053575) and the Kraken computing resource at the National Institute for Computational Sciences (supported by NSF grants 0711134, 0933959, 1041709, and 1041710 and the University of Tennessee). We acknowledge the Texas Advanced Computing Center (TACC) at The University of Texas at Austin for providing high-performance computing resources that have contributed to the research results reported in this paper. Additional computational resources were provided by the Center for Advanced Computing and Data Systems (CACDS, formerly Texas Learning and Computation Center, $\mathrm{TLC}^{2}$ ) and the Research Computing Center (RCC) at the University of Houston.

\section{SUPPLEMENTARY MATERIALS}

www.sciencemag.org/content/345/6204/1599/suppl/DC1 Materials and Methods

Supplementary Text

Figs. S1 to S12

Scheme S1

Tables S1 to S8

Movie S1

13 May 2014; accepted 8 August 2014

Published online 4 September 2014

10.1126/science. 1256018

\title{
Environmental filtering explains variation in plant diversity along resource gradients
}

\author{
Etienne Laliberté, ${ }^{1 *}$ Graham Zemunik, ${ }^{1}$ Benjamin L. Turner ${ }^{2}$
}

The mechanisms that shape plant diversity along resource gradients remain unresolved because competing theories have been evaluated in isolation. By testing multiple theories simultaneously across a >2-million-year dune chronosequence in an Australian biodiversity hotspot, we show that variation in plant diversity is not explained by local resource heterogeneity, resource partitioning, nutrient stoichiometry, or soil fertility along this strong resource gradient. Rather, our results suggest that diversity is determined by environmental filtering from the regional flora, driven by soil acidification during long-term pedogenesis. This finding challenges the prevailing view that resource competition controls local plant diversity along resource gradients, and instead reflects processes shaping species pools over evolutionary time scales.

F or decades, ecologists have sought to understand patterns in terrestrial plant diversity along environmental gradients (1). Prominent theories emphasize resource competition as a key driver of diversity (2-4). Alternatively, it has been proposed that variation in local plant diversity along gradients reflects the fil- tering of species that are poorly adapted to local environmental conditions (5-7), highlighting the importance of long-term evolutionary processes in shaping species pools and present-day patterns of plant diversity. These competing hypotheses have been considered in isolation, and further progress can be made only by considering the 